\title{
Long-Term Effects of Oral Antidiabetic Drugs During Pregnancy on Offspring: A Systematic Review and Meta-analysis of Follow-up Studies of RCTs
}

\author{
Wenneke van Weelden • Vincent Wekker (D) - Leon de Wit • \\ Jacqueline Limpens · Hilkka Ijäs · Aleid G. van Wassenaer-Leemhuis • \\ Tessa J. Roseboom • Bas B. van Rijn · J. Hans DeVries • \\ Rebecca C. Painter
}

Received: July 4, 2018 / Published online: August 30, 2018

(C) The Author(s) 2018

\section{ABSTRACT}

Introduction: Antidiabetic drugs (OADs) are increasingly prescribed to treat hyperglycaemia during pregnancy in women with gestational

Wenneke van Weelden and Vincent Wekker contributed equally.

Enhanced digital features To view enhanced digital features for this article go to https://doi.org/10.6084/ m9.figshare.6882128.

Electronic supplementary material The online version of this article (https://doi.org/10.1007/s13300018-0479-0) contains supplementary material, which is available to authorized users.

W. van Weelden · V. Wekker ( $₫)$. T. J. Roseboom . R. C. Painter

Department of Obstetrics and Gynaecology, Amsterdam UMC, University of Amsterdam, Amsterdam, The Netherlands e-mail: v.wekker@amc.nl

V. Wekker · A. G. van Wassenaer-Leemhuis ·

T. J. Roseboom · R. C. Painter

Amsterdam Reproduction and Development

Research Institute, Amsterdam UMC, Amsterdam,

The Netherlands

V. Wekker · T. J. Roseboom

Department of Clinical Epidemiology, Biostatistics and Bioinformatics, Amsterdam UMC, University of Amsterdam, Amsterdam, The Netherlands

V. Wekker · T. J. Roseboom

Amsterdam Public Health Research Institute,

Amsterdam UMC, Amsterdam, The Netherlands diabetes mellitus (GDM) or polycystic ovary syndrome (PCOS), even though long-term effects on offspring are unknown. This systematic review summarises the evidence of followup studies of randomised controlled trials (RCTs) reporting on long-term effects of prenatal exposure to OADs on offspring.

Methods: The MEDLINE, EMBASE and CENTRAL databases were searched from inception to April 2018 for the concepts antidiabetic agents and prenatal exposure (or pregnancy and offspring/child) in combination with an RCT search filter. RCTs evaluating post-neonatal health effects in offspring and comparing

L. de Wit · B. B. van Rijn

Department of Gynaecology and Obstetrics, Wilhelmina Children's Hospital Birth Centre, University Medical Centre Utrecht, Utrecht, The Netherlands

\section{J. Limpens}

Medical Library, Amsterdam UMC, University of Amsterdam, Amsterdam, The Netherlands

H. Ijäs

Department of Obstetrics and Gynaecology, Oulu University Hospital, Oulu, Finland

\section{A. G. van Wassenaer-Leemhuis}

Department of Neonatology, Emma Children's

Hospital, Amsterdam UMC, University of

Amsterdam, Amsterdam, The Netherlands

J. H. DeVries

Department of Endocrinology, Amsterdam UMC, University of Amsterdam, Amsterdam,

The Netherlands 
maternal treatment with an OAD with no treatment, placebo, an alternative OAD or insulin during pregnancy were eligible for inclusion. Two independent researchers selected, extracted and assessed the data. Metaanalyses were performed using a random effects model and the Cochrane Collaboration's risk of bias tool was used for quality assessment.

Results: Ten studies were included, with a maximal follow-up duration of 9 years, comprising 778 children of mothers with GDM or PCOS who were randomised to either metformin or insulin/placebo during pregnancy. Meta-analysis showed that children prenatally exposed to metformin were heavier compared to controls (standardised mean difference (SMD) 0.26 [95\% CI 0.11-0.41]), but not taller (SMD 0.10 [95\% CI -0.14-0.33]). Additionally, offspring body mass index (BMI) $z$ scores did not differ according to metformin exposure (mean difference 0.30 [95\% CI -0.01-0.61]). Individual small studies reported that prenatal exposure to metformin was associated with greater mid-upper arm, head and waist circumferences, biceps skinfolds, waist-to-height ratio, more arm fat, higher fasting glucose, ferritin and lower LDL cholesterol in offspring.

Conclusion: Prenatal exposure to metformin is associated with increased offspring weight, but not with height or BMI. Larger follow-up studies are needed to confirm and look into the implications of these findings.

Plain Language Summary: Plain language summary available for this article.

Keywords: Cardiometabolic health; Child development; Gestational diabetes; Insulin; Metformin; Oral antidiabetic drugs; Polycystic ovary; Pregnancy; Prenatal exposure; Syndrome; Systematic review

\section{PLAIN LANGUAGE SUMMARY}

Women are increasingly overweight and obese as they enter pregnancy, which means they are more prone to develop high blood sugars during their pregnancy. Therefore, more pregnant women are prescribed medication to lower their blood sugars. Tablets that lower blood sugar could cross the placenta to the baby as it grows in the mother's womb. Therefore, it is important to know whether these tablets directly affect the baby or cause any permanent changes to the baby's health. Here, we thoroughly searched the scientific literature for available findings that could help us understand whether babies whose mothers had taken these tablets while they were pregnant were in any way different in terms of growth or health as they grew up. We found 10 studies, including a total of 778 children. Children whose mothers had taken blood-sugar-lowering tablets while they were pregnant were heavier but not taller compared to children whose mothers had taken no tablets, but had injected insulin or taken a mock tablet (placebo). We could not find enough studies to help us draw conclusions on any of the other health effects. In the future, more and larger studies could help find out more about other health effects among children of mother on blood-sugar-lowering tablets. Also, it would be helpful if we could understand whether the fact that children are heavier when their mothers took blood-sugar-lowering tablets means they are more likely to be obese or to have chronic disease in later life. In the meantime, our study will help doctors inform pregnant women who need blood-sugar-lowering tablets.

\section{INTRODUCTION}

The global prevalence of gestational diabetes mellitus (GDM), type 2 diabetes mellitus, polycystic ovary syndrome (PCOS) and metabolic syndrome (MetS) is rising as the obesity pandemic expands [1]. Oral antidiabetic drugs (OADs) are increasingly being used in pregnancy to reduce the risk of complications associated with these diseases [2].

The International Diabetes Federation estimated that some form of hyperglycaemia was present in $16.7 \%$ of the pregnancies in 2017 [3]. Dietary and lifestyle adjustments are the first line of treatment for GDM [2]. In recent years, the use of OADs as an alternative for insulin as pharmacological treatment has risen and the 
use of metformin and glibenclamide has been incorporated in clinical guidelines [4]. OADs are attractive because of their lower costs and better compliance due to the oral administration compared to insulin [5]. The current guideline of the International Federation of Gynaecology and Obstetrics advises insulin, glibenclamide and metformin as effective and safe treatments when lifestyle modifications are insufficient for GDM during the third trimester. In this guideline metformin is recommended above other OADs [2].

The National Institute for Health and Care Excellence guideline only suggests metformin as an alternative for insulin and discourages the use of other OADs [6]. However, the most recent Cochrane review comparing metformin, glibenclamide and acarbose did not report any of the OADs to be superior $[7,8]$.

Metformin lowers plasma glucose levels by reducing gluconeogenesis in the hepatocytes. It inhibits the mitochondrial output of adenosine triphosphate (ATP) which is needed in multiple steps of glucose synthesis, and consequently increases the ratio between adenosine $5^{\prime}$ monophosphate and ATP which inhibits lipid synthesis and increases insulin sensitivity [9].

Recommendations regarding OADs in pregnancy are based on effectiveness and short-term outcomes, including glycaemic control and perinatal outcomes. Unlike insulin, some OADs (including glibenclamide, metformin, tolbutamide and chlorpropamide) cross the placenta $[10,11]$. Metformin concentrations in the umbilical cord have been found to be similar or even higher than concentrations in maternal blood [12, 13]. Meta-analysis of human cohort studies report no increased risks of major malformations $[14,15]$. The placental passage of OADs can potentially have direct and permanent effects on the foetus's developing physiology, which in turn could affect the offspring's health in childhood and later life [16, 17].

There is no up-to-date overview aggregating the evidence on the long-term effects of prenatal exposure to OADs on the health of children based on follow-up of randomised controlled trials (RCTs). Therefore, the aim of this systematic review is to examine the scientific evidence published to date in RCTs on the long-term effects of maternal usage of OADs during pregnancy on their offspring compared to non-treatment, placebo, other OADs or insulin.

\section{METHODS}

\section{Study Design}

This systematic review was conducted following the Cochrane Handbook for Systematic Reviews of Interventions and reported according the Preferred Reporting Items for Systematic Reviews and Meta-Analyses (PRISMA) statement $[18,19]$. The review protocol was registered in March 2016 , in the international prospective register of systematic reviews (PROSPERO: CRD42016032674) (Online Appendix 1).

\section{Data Sources and Searches}

A medical information specialist (JL) performed a systematic search in OVID MEDLINE (including Epub Ahead of Print, In-Process \& Other Non-Indexed Citations), OVID EMBASE and the Cochrane Central Register of Controlled Trials (CENTRAL) from inception to 27 April 2018 to identify RCTs on effects of prenatal exposure to OADs on the offspring. To this end we searched for controlled terms (i.e. MeSH) and free text terms for (1) OADs including metformin and (2) prenatal exposure (or pregnancy and offspring/child) combined with (3) a search filter adapted from the Cochrane Collaboration to identify RCTs [20]. No language or date restrictions were applied. ClinicalTrials.gov was searched to potentially identify trial results that were not reported elsewhere. We crosschecked the reference lists and the articles citing the identified relevant papers to find additional publications including grey literature. Finally we searched for systematic reviews to ensure that no systematic review with a similar research question was recently published. The complete search strategies are presented in Online Appendix 2. 


\section{Study Selection}

RCTs that reported on post-neonatal health effects in offspring and compared maternal treatment with an OAD with no treatment, placebo, an alternative OAD or insulin during pregnancy were considered eligible for inclusion for this systematic review. Non-RCT design studies, animal studies, studies in an incorrect population, studies that did not report on outcomes in offspring and studies only reporting on neonatal outcomes were excluded from this systematic review. Two authors (VW, WvW) independently screened all potential articles and conference abstracts on title and abstract using COVIDENCE [21]. Disagreements were resolved by discussion or consulting a third author (RP). Two authors (VW, WvW) independently screened the full text of all remaining articles to determine the final selection.

\section{Data Extraction and Quality Assessment}

Using a standardised data extraction form (Online Appendix 3), two authors (VW, WvW) independently performed data extraction. If data was not presented in the original publication in a way that would allow aggregation or if relevant outcomes were not reported at all, authors of the articles were contacted by e-mail.

The Cochrane Collaboration's tool for assessing risk of bias was used to assess the methodological quality of the included studies [22]. Discrepancies in data extraction and quality assessment were solved by discussion and consulting a third author (RP).

Grading of Recommendations Assessment, Development and Evaluation (GRADE) was used to assess the strength of the body of evidence for all outcomes that are included in metaanalysis [23].

\section{Data Synthesis and Analysis}

Reported outcomes of similar domains were combined in summary tables (Online Appendix 4). Outcomes that were reported by multiple studies were included in random-effects metaanalyses using the Inverse Variance method in
Review Manager (RevMan 5.3) [24]. Meta-analyses in which more than two studies could be included are presented in the results, including sensitivity analyses for treatment indication. Outcomes reported at the same age were presented as unadjusted mean values and 95\% confidence intervals (CI). Outcomes reported at different ages were presented as standardised mean differences and 95\% CI. Heterogeneity was evaluated using the $I^{2}$ statistic. If the same study population was used to report on similar outcomes at the same age in multiple follow-up studies, the study with the largest number of participants was used to report on overlapping outcomes. If the same outcome was reported at different ages, the study with the largest number of participants was included in the metaanalysis to increase statistical power to find differences between the treatment groups. In case of discrepancy between the reported $p$ values in the original articles and our own analyses, the $p$ values calculated using Review Manager were reported in this systematic review.

\section{RESULTS}

\section{Literature Search}

Of the 305 publications identified in the literature search, ten publications were eligible for inclusion in this systematic review and six publications were eligible for meta-analysis (Fig. 1) [25-34]. Further follow-up studies of the completed EMPOWaR, MiTy trial and PregMet trials are planned for the future [35-37]. One upcoming trial (NCT02947503) comparing metformin to usual care for GDM was identified in the trial registry. This trial has planned follow-up of the offspring up to 18 years of age. No recent systematic review comprising the same research question was identified.

\section{Study Characteristics}

The ten included studies are follow-up studies of five RCTs conducted between 2000 and 2010 [37-41]. This article is based on previously 


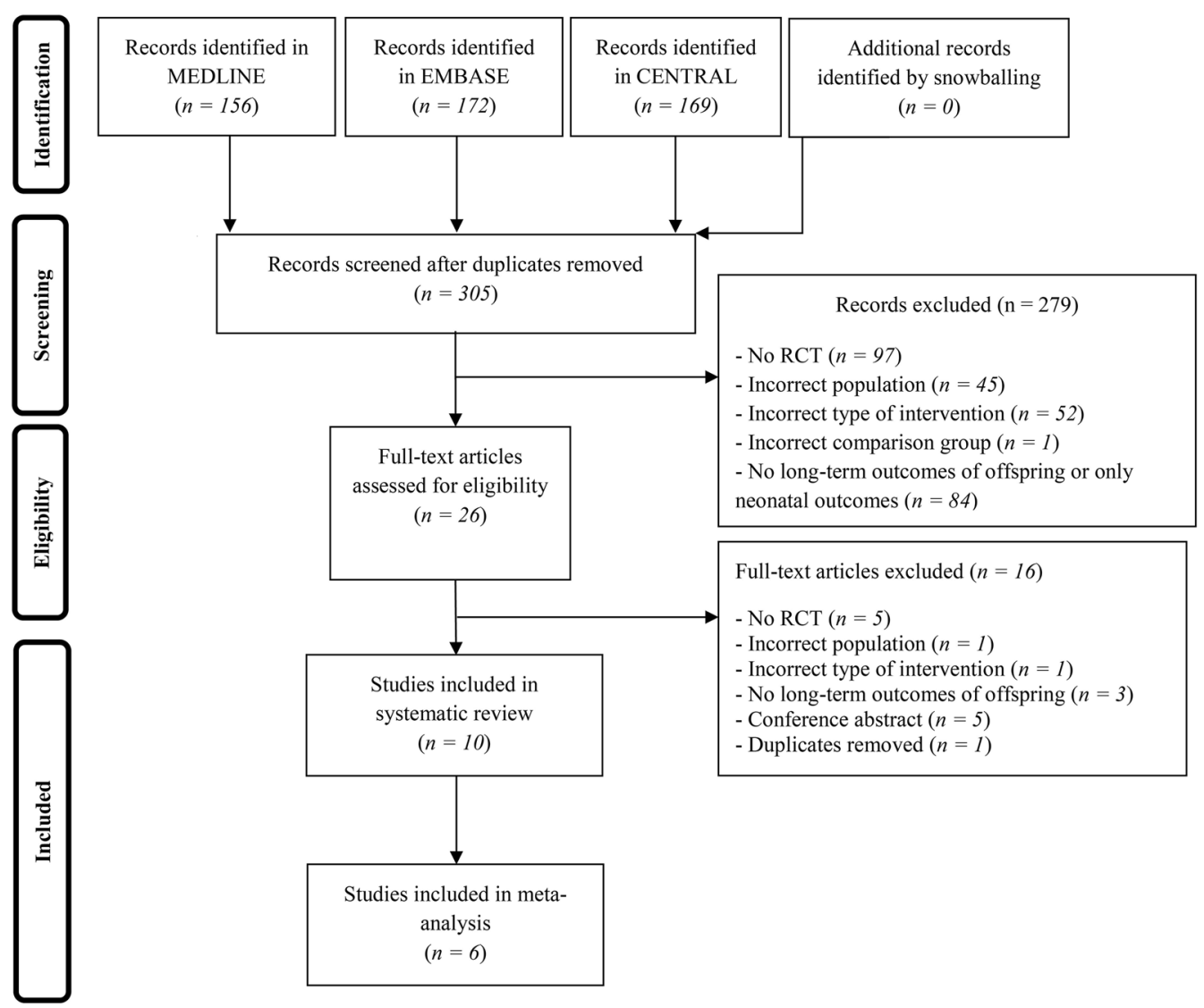

Fig. 1 Flowchart

conducted studies and does not contain any studies with human participants or animals performed by any of the authors. However, all included studies were approved by an ethical committee. Characteristics of the women that participated in the original RCTs are summarised in Table 1. A total of 1360 pregnant women diagnosed with either PCOS $(n=313)$ or GDM $(n=1047)$ were randomised to an intervention group that was treated with metformin or a control group that was treated with placebo [37, 41] or insulin [38-40]. No followup studies were identified of RCTs testing effects of other OADs than metformin. GDM was diagnosed before entering the study, and women were eligible for inclusion if they had not achieved euglycaemia with dietary and lifestyle management. The criteria for GDM varied between the studies, as described in Table 1. PCOS was diagnosed according to the revised Rotterdam Criteria [42]. Mean maternal age at enrolment in the original trials was 31.8 years [95\% CI 31.5-32.0]. Mean maternal body mass index (BMI) at enrolment was $30.5 \mathrm{~kg} / \mathrm{m}^{2}$ [95\% CI 30.2-30.9]. Characteristics of the offspring involved in the included studies are summarised in Table 2. All follow-up studies were performed between 2004 and 2016. Four studies included offspring of the MiG trial $[25-27,33]$ and two included offspring of the trial performed by Tertti et al. [30, 31]. Offspring of both of the original trials performed by Vanky et al. $[37,41]$ were included in a total of three follow-up studies [28, 32, 34]. A total of 778 children, aged 6 months to 9 years, were included in the follow-up studies. Treatment with metformin was started between 5 and 34 weeks of gestation and was continued until delivery. All reported outcomes have been included in this systematic review. 


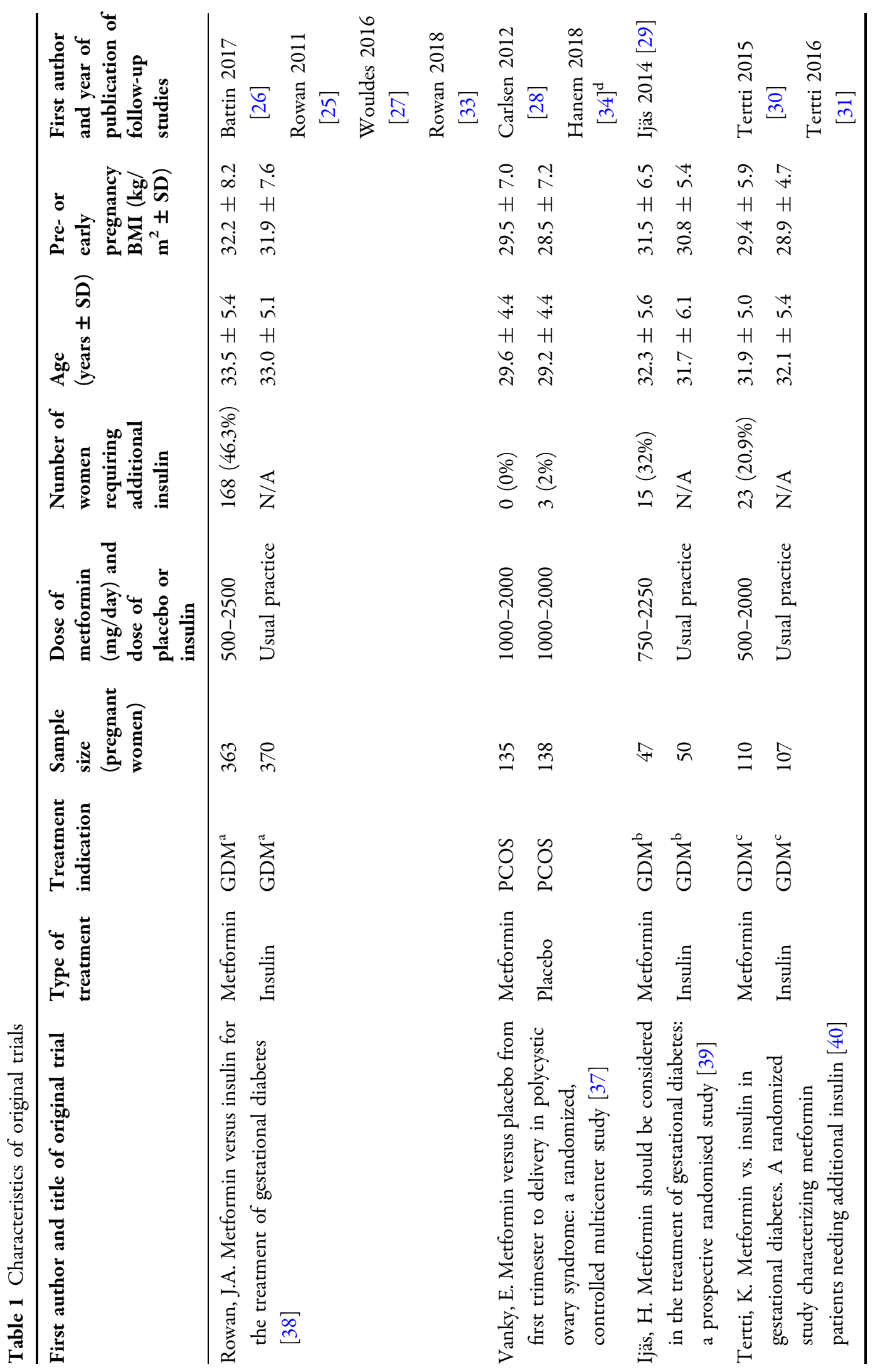




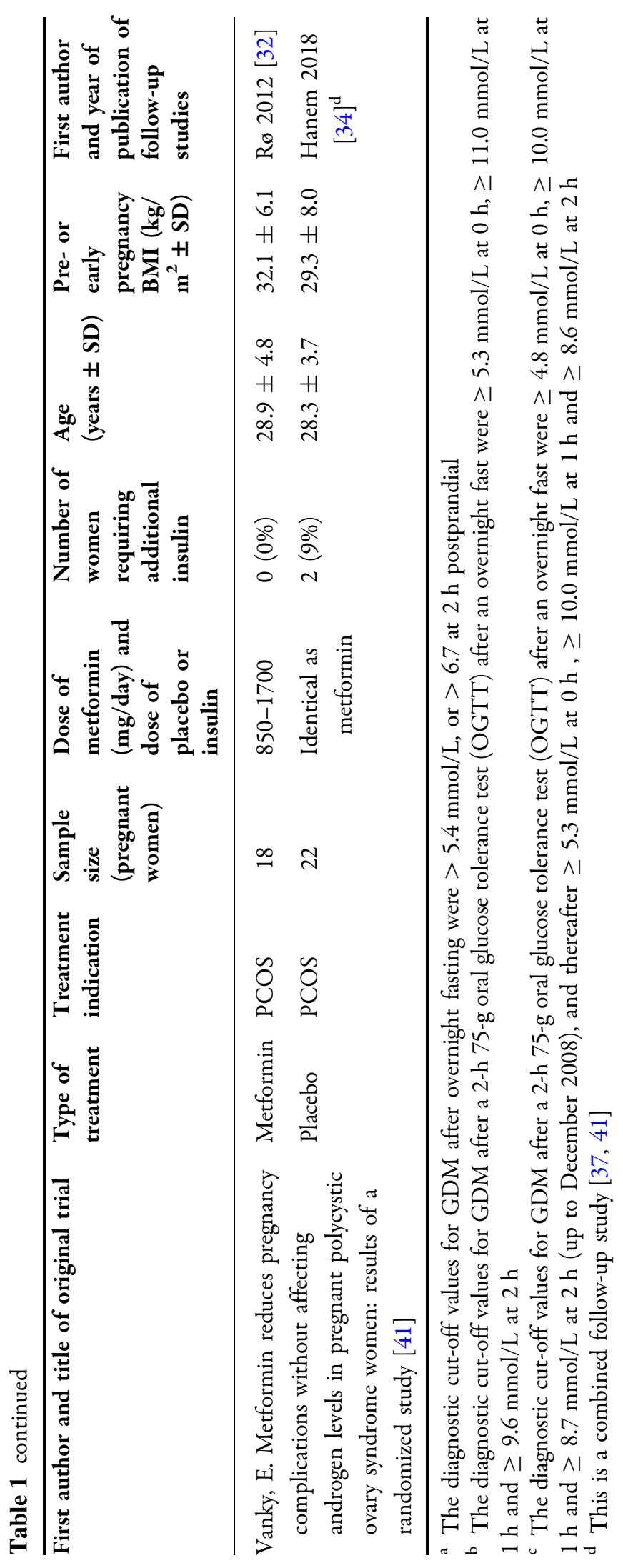




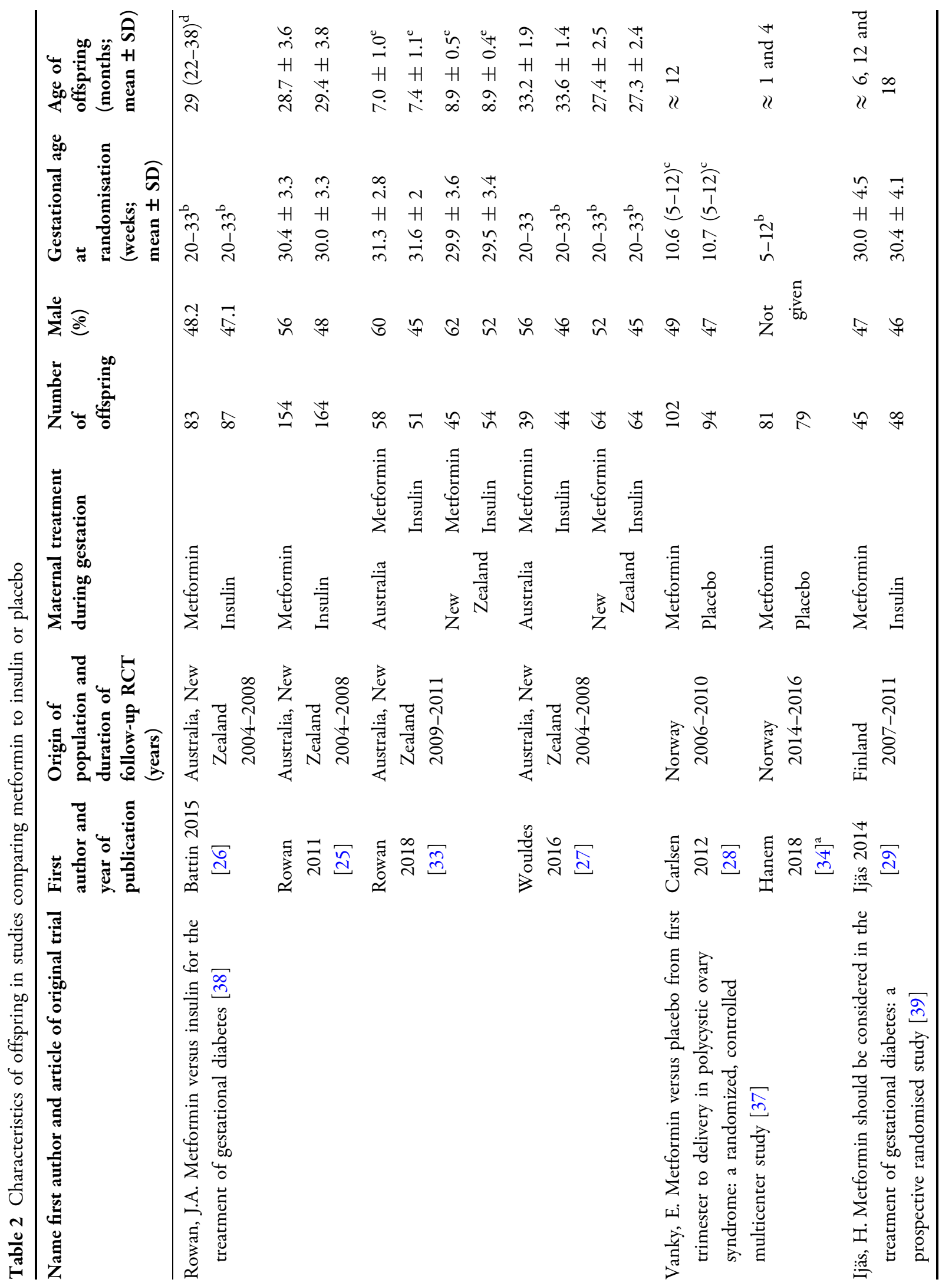




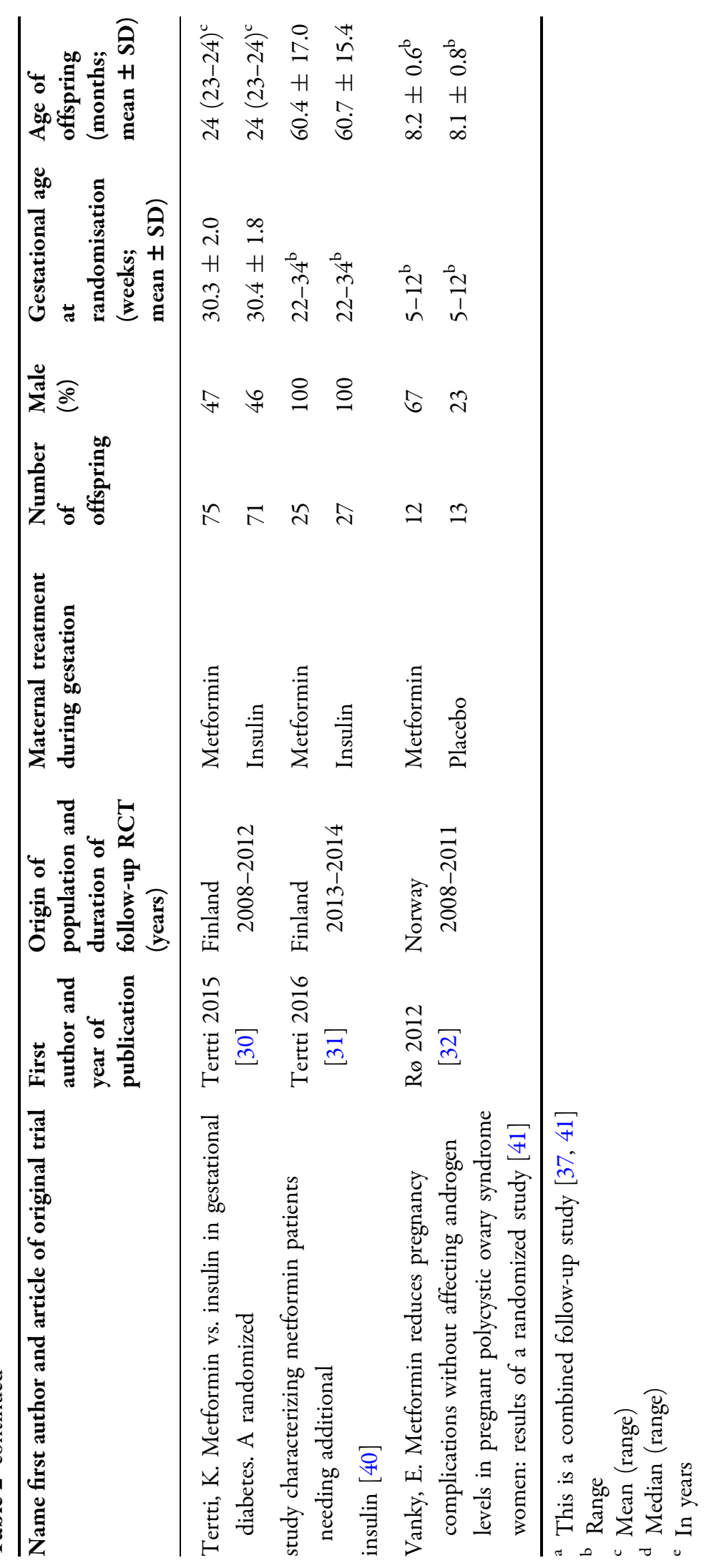




\section{Selection Bias}

Several studies adjusted for possible selection bias based on differences in baseline characteristics of the follow-up population. Carlsen et al. reported body weight adjusted for gestational age, birth weight, the duration of breastfeeding, maternal BMI and height, and maternal smoking status. Ijäs et al. reported body weight at 18 months adjusted for maternal pre-pregnancy BMI. Battin et al. reported blood pressure adjusted for gestational age, height, weight and arm measurements. Rowan et al. [25] reported upper-arm circumference, biceps and subscapular skinfolds adjusted for gestation age, gender, ethnicity, maternal glucose control during pregnancy and fat mass and fat-free mass (FFM) adjusted for height, weight and age. Wouldes et al. reported Bayley Scales of Infant Development V.2 (Bayley-II), mental development index (MDI) and psychomotor development index (PDI) adjusted for social characteristics at birth and follow-up, neonatal characteristics, offspring age and childhood illnesses at follow-up, and maternal glycaemic control. Rowan et al. [33] reported unadjusted results, but noted that adjustments for age, ethnicity and gender had no influence on their results.

\section{Multiple Reporting in the Same Population}

Three studies evaluated outcomes in offspring of the MiG trial [38] around the same age [25-27]. Data on weight and height were overlapping in these studies. Rowan et al. [25] included the largest number of children, therefore we used this study to report on weight and height. Hanem et al. reported on anthropometrics of offspring who were also included in the study by Carlsen et al. and Rø et al., but these measurements were performed at different ages. Two studies evaluated outcomes in offspring of the Tertti trial, but the outcomes of interest did not overlap.

\section{Unpublished Data}

Ijäs et al. provided unpublished data on BMI and gender at 6,12 and 18 months. We used the 'WHO child growth standards' and associated
LMS technique to calculate BMI standard deviation scores (SDS) for this population [43].

\section{Anthropometric Measurements}

Results on anthropometrics and body composition are summarised in Tables S1 and S2 of the electronic supplementary material (Online Appendix 4).

\section{Body Weight}

Seven studies reported on body weight $[25,28,29,31-34]$ of which five studies with a total of 684 children could be included in a meta-analysis (Fig. 2) [25, 28, 29, 31, 32]. Metformin-exposed offspring had a higher body weight compared to insulin/placebo-exposed offspring (standardised mean difference (SMD) 0.26 [95\% CI 0.11-0.41]). The included studies showed low heterogeneity $\left(I^{2}=0 \%, P=0.40\right)$.

Ijäs et al. reported no differences in body weight at 6 months of age $(8.28 \pm 0.99$ vs. $7.93 \pm 0.99 \mathrm{~kg} ; \quad P=0.071)$, but a statistically significant higher body weight was reported at 12 and 18 months of age in the metformincompared to insulin-exposed offspring $(10.47 \pm 1.49$ vs. $9.85 \pm 1.26 \mathrm{~kg} ; P=0.038$ and $12.05 \pm 1.87$ vs. $11.32 \pm 1.45 \mathrm{~kg} ; \quad P=0.04)$. Similar results at age 18 months were found when adjusted for maternal pre-pregnancy BMI. Carlsen et al. reported a statistically significantly higher body weight at 12 months of age in the metformin- compared to placebo-exposed offspring $(10.2 \pm 1.2$ vs. $9.7 \pm 1.1 \mathrm{~kg}$; $P=0.003)$. Rowan et al. [25] reported no significant difference in body weight at 2 years of age between the metformin- and insulin-exposed offspring $(14.3 \pm 2.1$ vs. $14.0 \pm 2.2 \mathrm{~kg}$; $P=0.18$ ). Hanem et al. reported a significantly higher SDS for body weight at 4 years of age in the metformin- compared to the placebo-exposed offspring (0.44 [95\% CI $0.22-0.66]$ vs. 0.06 [95\% CI $-0.16-0.28] ; P=0.017$ ). Tertti et al. [31] reported no difference in body weight in boys at 5 years of age between the metformin- and insulin-exposed offspring $(21.2 \pm 5.2$ vs. $20.2 \pm 4.9 \mathrm{~kg} ; P=0.61)$. Rø et al. reported no differences in body weight at 8 years of age between the metformin- and placebo-exposed offspring $\quad(32.3 \pm 5.2$ vs. 


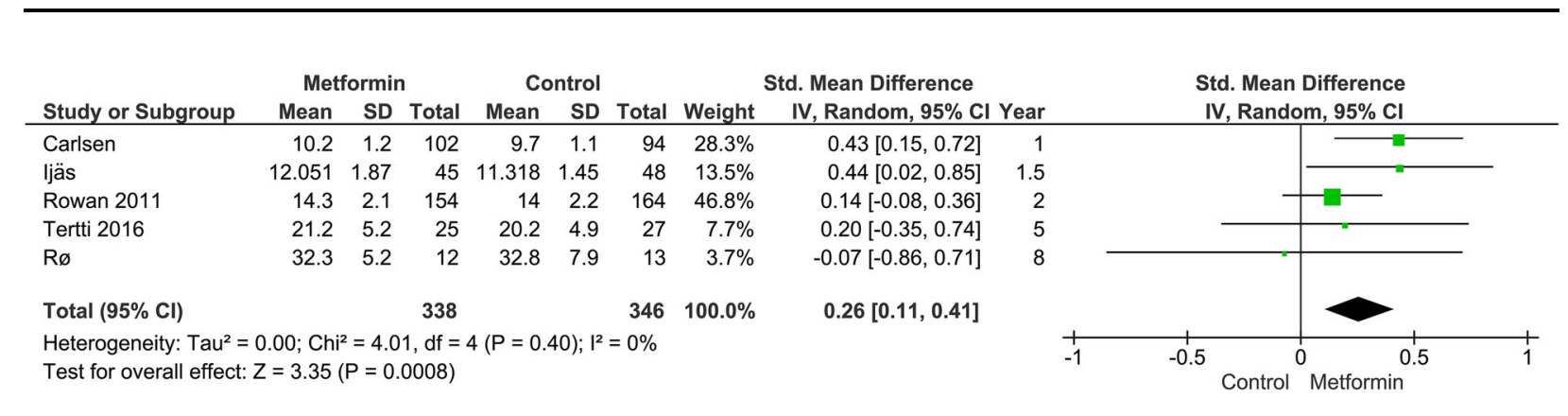

Fig. 2 Forest plot of meta-analysis on mean body weight

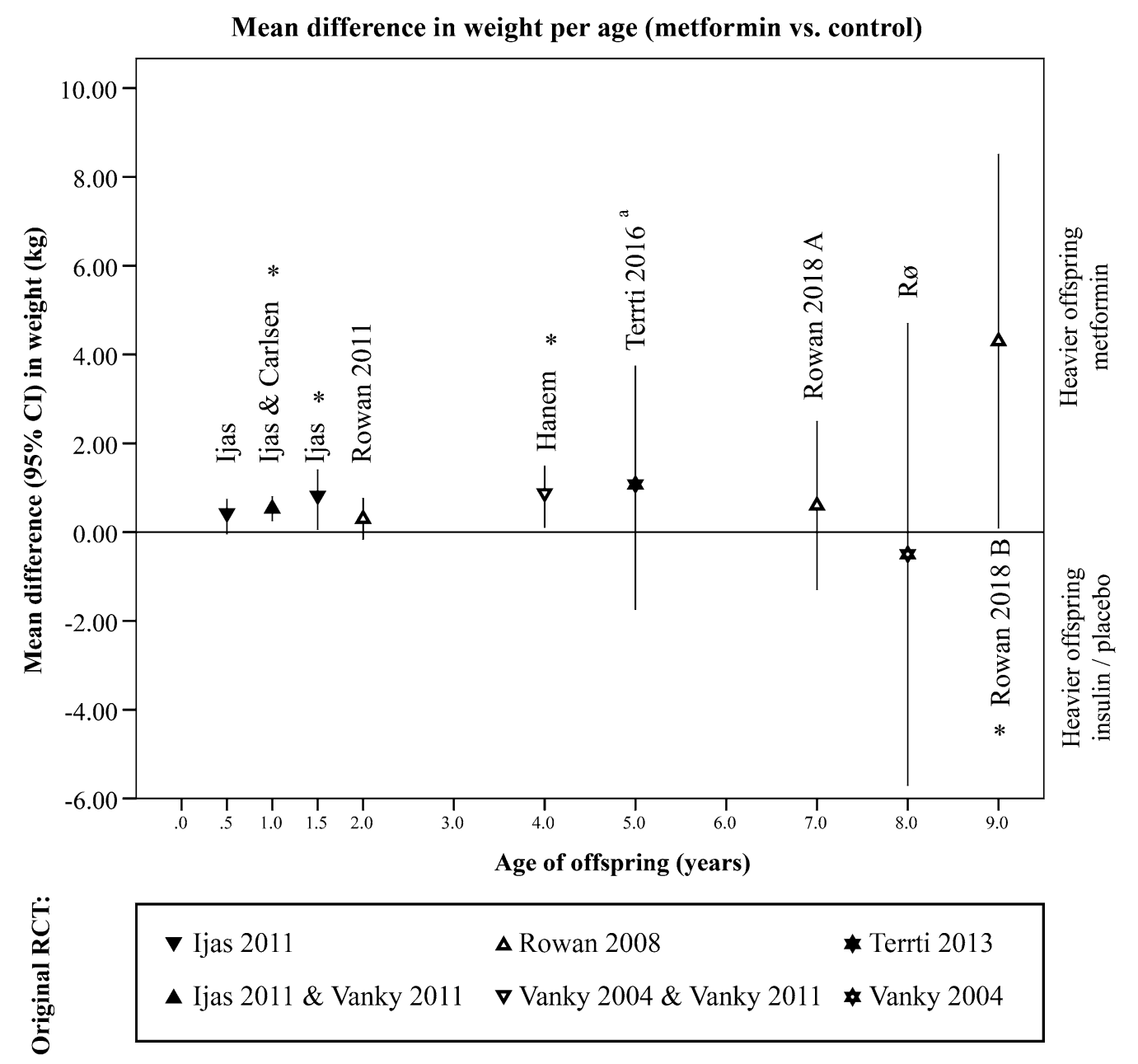

Fig. 3 Mean difference in weight $(\mathrm{kg})$ per age (years) (metformin vs. control) ${ }^{*} P<0.05$; ${ }^{a}$ only boys

$32.8 \pm 7.9 \mathrm{~kg} ; \quad P=0.85)$. Rowan et al. [25] reported a significantly higher body weight at 9 years of age in the metformin- compared to the insulin-exposed offspring in the subgroup born in New Zealand $(37.0 \pm 12.6$ vs.
$32.7 \pm 7.7 \mathrm{~kg} ; \quad P=0.049)$. These differences were not found in the Australian subgroup at age 7 . The mean differences in weight at all reported ages is chronologically displayed in Fig. 3. 


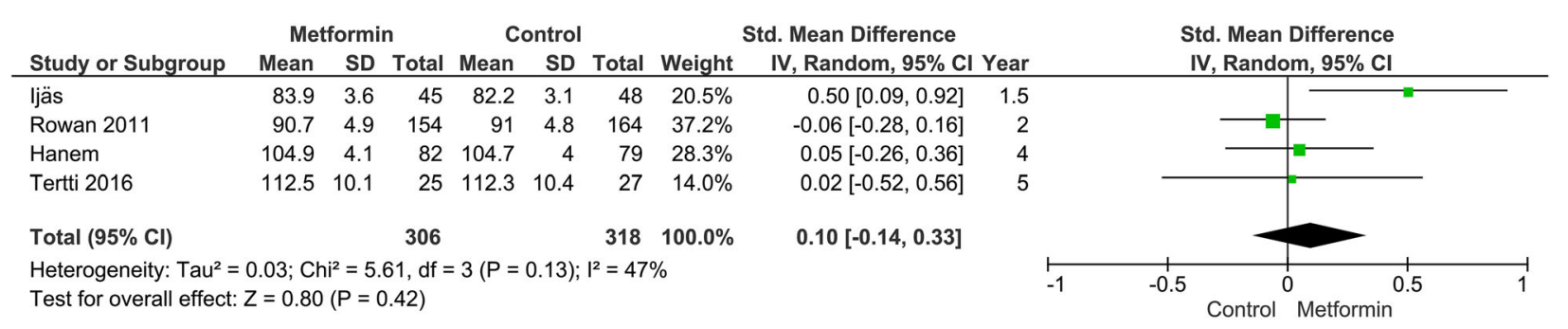

Fig. 4 Forest plot of meta-analysis on mean height

\section{Height}

Six studies reported on height [25, 29, 31-34] of which four studies with a total of 624 children could be included in a meta-analysis for height (Fig. 4) [25, 29, 31, 34]. No difference was found in height between the metformin- and insulin/placebo-exposed offspring (SMD 0.10 [95\% CI -0.14-0.33]). The included studies showed moderate heterogeneity $\left(I^{2}=47 \%, P=0.13\right)$. Ijäs et al. reported no differences in height at 6 and 12 months of age, but a significantly greater height was reported at 18 months of age in the metformin- compared to insulin-exposed offspring $(83.9 \pm 3.6$ vs. $82.2 \pm 3.1 \mathrm{~cm} ; P=0.023)$. Rowan et al. [25] reported no difference in height at 2 years of age between the metforminand insulin-exposed offspring $(90.7 \pm 4.9$ vs. $91 \pm 4.8 \mathrm{~cm} ; P=0.68)$. Hanem et al. reported no differences in height at 4 years of age between the metformin- and insulin-exposed offspring (SDS 0.18 [95\% CI $-0.03-0.38]$ vs. 0.11 [95\% CI $-0.10-0.32] ; P=0.651$ ). Tertti et al. [31] reported no differences in height in boys at 5 years of age between those exposed to metformin or insulin $(112.5 \pm 10.1$ vs. $112.3 \pm 10.4 \mathrm{~cm} ; P=0.95)$. Rø et al. reported no differences in SDS for height at 8 years of age between the metformin- and placebo-exposed offspring $\quad(0.75 \pm 0.77$ vs. $0.65 \pm 0.56 \mathrm{~cm}$;
$P=0.79$ ). Rowan et al. [33] reported no differences in height between the metformin- and insulin-exposed offspring in the New Zealand subgroup at 9 years of age (137.5 \pm 7.4 vs. $135.4 \pm 6.6 ; P=0.13)$ and Australian subgroup at 7 years of age $(124.5 \pm 5.2$ vs. $124.5 \pm 5.0$; $P=0.99$ ).

\section{Body Composition}

Six studies reported on body composition $[25,29,31-34]$ of which three studies with a total of 300 children could be included in a meta-analysis for BMI SDS scores [29, 31, 34]. No difference was found in SDS for BMI between the metformin- and placebo/insulinexposed offspring (0.30 [95\% CI $-0.01-0.61]$; $P=0.06$ ) (Fig. 5). For Ijäs et al.'s study, offspring at the age of 18 months were included in this meta-analysis. The studies showed low heterogeneity $\left(I^{2}=25 \%, P=0.26\right)$. Ijäs et al. reported no difference in mean head circumference or ponderal index $\left(\frac{\text { Weight }(\mathrm{kg})}{\text { Height }(\mathrm{m})^{3}}\right)$ at 6,12 and 18 months of age between the metformin- and insulin-exposed offspring. Rowan et al. [25] reported a significantly higher mid-upper arm circumference $(17.2 \pm 1.5$ vs. $16.7 \pm 1.5 \mathrm{~cm}$; $P<0.01)$ and biceps skinfolds $(6.0 \pm 1.9$ vs. $5.6 \pm 1.7 \mathrm{~mm} ; P=0.05)$ at 2 years of age in the

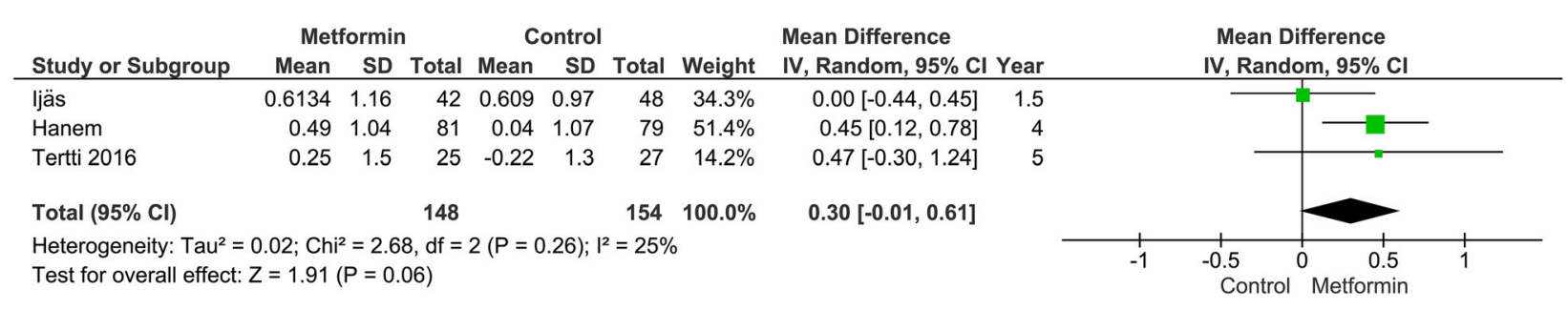

Fig. 5 Forest plot of meta-analysis on BMI standard deviation scores 
metformin- compared to insulin-exposed offspring. No difference in chest, waist, head and hip circumferences, triceps and subscapular skinfolds and outcomes of the bioimpedance analysis and dual energy x-ray absorptiometry (DEXA) scans was reported. Hanem et al. reported a significantly higher head circumference at 1 year of age (47.0 [95\% CI 46.7-47.2] vs. 46.5 [95\% CI $46.3-46.8] \mathrm{cm} ; P=0.026)$ and a significantly higher SDS for BMI at 4 years of age (0.49 [95\% CI $0.25-0.72]$ vs. 0.04 [95\% CI $-0.20-0.28] ; \quad P=0.010)$ in the metformincompared to the placebo-exposed offspring. Tertti et al. [31] reported no difference in waistto-hip circumference ratio in boys at 5 years of age between the metformin- and insulin-exposed offspring $(0.92 \pm 0.05$ vs. $0.91 \pm 0.08$; $P=0.32$ ). Rø et al. reported no difference in SDS for waist-to-height ratio at 8 years of age between the metformin- and placebo-exposed offspring $\quad(0.88 \pm 0.03 \quad$ vs. $0.89 \pm 0.05$; $P=0.53)$. No differences in outcomes of the DEXA scans were reported. Rowan et al. [33] reported a significantly higher mid-upper arm circumference $(23.0 \pm 4.3$ vs. $21.2 \pm 2.9 \mathrm{~cm}$; $P=0.02)$, waist circumference $(69.1 \pm 12.2$ vs. $64.2 \pm 8.4 \mathrm{~cm} ; P=0.04)$, waist-to-height ratio $(0.51 \pm 0.08$ vs. $0.47 \pm 0.05 ; P=0.02)$ and arm fat $(1568 \pm 801$ vs. $1285 \pm 534 \mathrm{~g} ; P=0.047)$ at 9 years of age in metformin- compared to insulin-exposed offspring, in the New Zealand subgroup. These differences were not found in the Australian subgroup at age 7 .

\section{Sensitivity Analyses}

The results of the sensitivity meta-analyses for treatment indication are reported in Online Appendix 4. The meta-analysis including three studies $[25,29,31]$ reporting on offspring of women with GDM showed that metformin-exposed offspring had a higher body weight (SMD 0.20 [95\% CI 0.02-0.39]; $P=0.03$ ) in comparison to insulin-exposed offspring, but no difference was found for height or BMI SDS scores. The meta-analysis including two studies [28, 32] reporting on offspring of women with PCOS showed no difference in weight between metformin- and placebo-exposed offspring. Only one study [34] reported on height and BMI SDS scores in offspring of PCOS women, therefore no sensitivity meta-analysis was performed for these outcomes. Sensitivity analyses for gender as planned in the study protocol (Online Appendix 1) could not be performed because of a lack of data published separately for boys and girls.

\section{Cardiometabolic Health Parameters}

Results of biochemical outcomes and blood pressure are summarised in Table S3 of the electronic supplementary material (Online Appendix 4).

\section{Biochemical Outcomes}

$\mathrm{Rø}$ et al. reported a significantly higher fasting glucose at 8 years of age in the metformin compared to placebo exposed offspring $(4.93 \pm 0.31$ vs. $4.60 \pm 0.35 \mathrm{mmol} / \mathrm{L} ; P=0.02)$ and a significant lower LDL cholesterol $(2.42 \pm 0.69$ vs. $2.99 \pm 0.46 \mathrm{mmol} / \mathrm{L} ; P=0.02)$ [32]. No differences in glucagon levels, insulin levels, c-peptide, HDL cholesterol, total cholesterol, triglycerides, leptin, ghrelin, plasminogen activator inhibitor-1 (PAI-1), resistin, visfatin, HOMA-IR, HOMA- $\beta$ and QUICKI were reported. Rowan et al. [33] reported a significantly higher ferritin level at 9 years of age in metformincompared to insulin-exposed offspring in the New Zealand subgroup (52 [95\% CI 40-70] vs. 40 [95\% CI 28-59) $\mu \mathrm{g} / \mathrm{L} ; P<0.01]$. No other differences in fasting glucose, HbA1c, insulin resistance, lipids, transaminases, leptin and adiponectin were reported in the New Zealand subgroup. Only fasting glucose was measured in the Australian subgroup and was not different between the metformin- and insulin-exposed offspring [33].

\section{Blood Pressure}

Battin et al. reported no difference in blood pressure at 2 years of age between the metformin- and insulin-exposed offspring, but only reported this in a graph [26]. Rø et al. reported a trend towards higher systolic blood pressure at 8 years of age in the metformin- compared to placebo-exposed offspring $(106 \pm 6 \quad$ vs. $101 \pm 7 \mathrm{mmHg} ; P=0.05)$ and no difference in 
diastolic blood pressure $(66 \pm 7 \quad$ vs. $65 \pm 3$ mmHg; $P=0.65$ ) [32].

\section{Social-, Motor- or Neurodevelopment}

Results on social-, motor- or neurodevelopment are summarised in Table $\mathrm{S} 4$ of the electronic supplementary material (Online Appendix 4).

Ijäs et al. reported no difference in results for the motor-, social- and linguistic development at 18 months of age between the metforminand insulin-exposed offspring [29]. Tertti et al. [30] reported no difference in Bayley Scales of Infant and Toddler Development (Bayley-III) scores and the Hammersmith Infant Neurological Examination at 2 years of age between the metformin- and insulin-exposed offspring [30]. Wouldes et al. reported no differences in MDI (Bayley-II) in children from New Zealand $(83.6 \pm 15.2$ vs. $86.9 \pm 16.0)$ and Australia $(102.5 \pm 16.5$ vs. $98.4 \pm 16.6)$ at 2 years of age between the metformin- and insulin-exposed offspring, with a combined $P$ value of 0.87 . In addition, no differences in PDI in children from New Zealand $(83.4 \pm 13.8$ vs. $85.2 \pm 14.8)$ and Australia $(105.6 \pm 11.5$ vs. $99.9 \pm 17.2)$ was reported, with a combined $P$ value of 0.38 [27].

\section{Testicular Volume}

Results on testicular volume are summarised in Table S5 of the electronic supplementary material (Online Appendix 4).

Tertti et al. [31] reported no difference in SDS for left or right testicular volume, measured with a orchidometer (Left: $1.81 \pm 0.4$ vs. $1.78 \pm 0.3$, $P=0.74 ; \quad$ Right: $1.84 \pm 0.6$ vs. $1.80 \pm 0.4$, $P=0.86$ ), ultrasonography (Left: $0.93 \pm 0.3$ vs. $0.86 \pm 0.3, \quad P=0.40 ; \quad$ Right: $0.89 \pm 0.4 \quad$ vs. $0.87 \pm 0.3, \quad P=0.92$ ) and a ruler (Left: $1.72 \pm 0.53$ vs. $1.60 \pm 0.43, P=0.50$; Right: $1.74 \pm 0.74$ vs. $1.67 \pm 0.45, P=0.90)$, when comparing boys of 5 years of age between the metformin- and insulin-exposed offspring [31].

\section{Quality Assessment}

The quality assessment, including explanations of the authors' judgement, and risk of bias

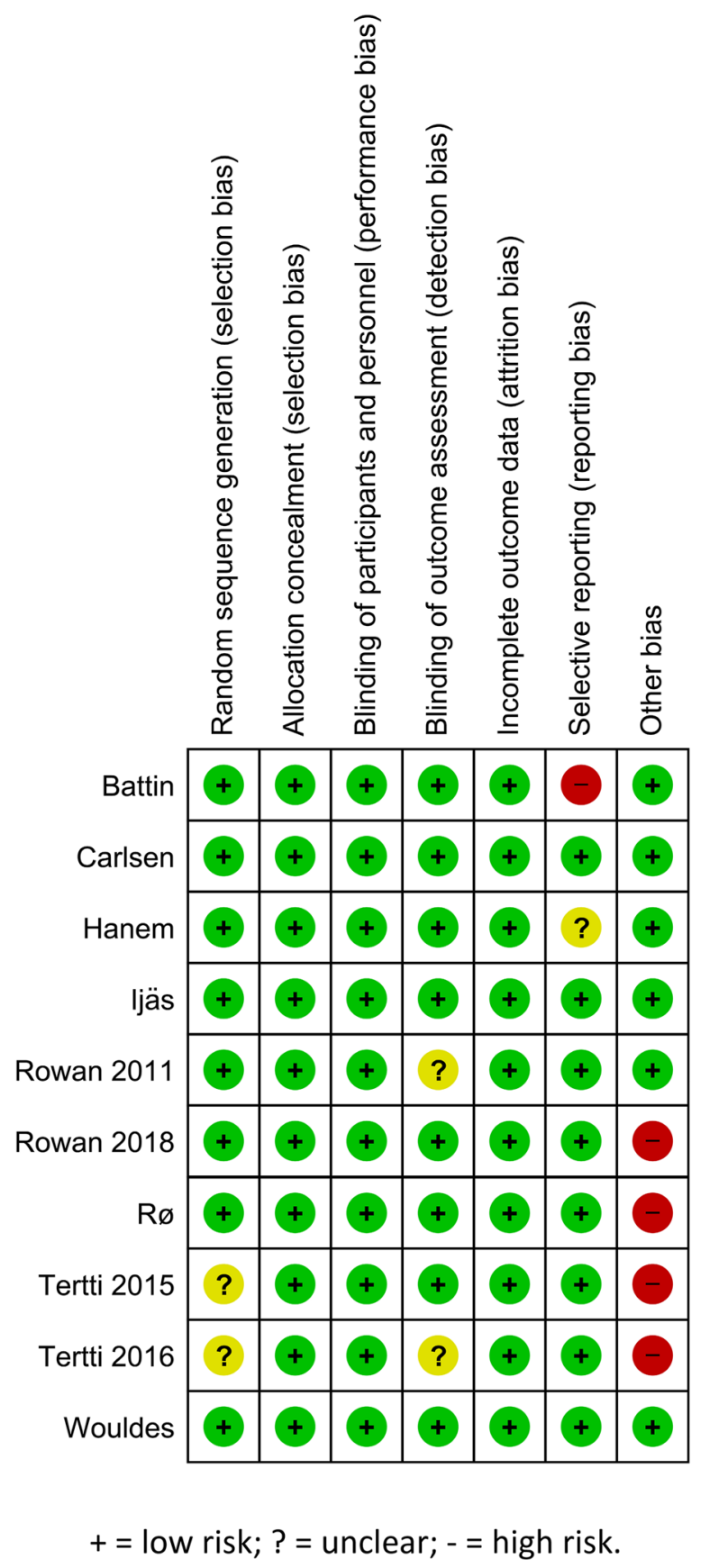

Fig. 6 Risk of bias graph: + low risk, ? unclear, - high risk

graph of included studies are shown in Fig. 6 and Table S6 of the electronic supplementary material (Online Appendix 4). We did not see any relation between study quality and the direction of the outcomes. The quality of the evidence that was included in the meta-analyses 
for body weight, height and BMI SDS scores was 'moderate' based on GRADE. The corresponding GRADE table is reported in Online Appendix 5 [23].

\section{DISCUSSION}

We performed a systematic review of RCTs comparing the long-term outcomes of children who were prenatally exposed to OADs with insulin or placebo during gestation. Our search could only identify studies on metformin, since there are no follow-up studies of RCTs including children exposed to other OADs during gestation. Meta-analyses showed an increased body weight in children who were prenatally exposed to metformin. A trend that did not achieve statistical significance was found for higher BMI SDS scores in metformin-exposed offspring as well. Other outcomes, including other measures of body composition, neurodevelopmental outcome and of cardiometabolic health, were not consistently affected, or investigated by single studies. The finding of increased weight is in line with an animal study showing that a high-fat diet in mice exposed to metformin during gestation led to increased body weight in the offspring [44]. In these mice, metformin exposure in utero led to increased gene expression of Insig-1, associated with lipogenesis and adiposity [44]. Since metformin reduces lipogenesis in hepatocytes, this suggests a permanent compensatory upregulation of genes that increase lipogenesis [9]. These programming effects resemble those that are seen in undernutrition during gestation that lead to longterm metabolic effects [45]. Elevated plasma glucose, which was present in mice exposed to metformin in utero, was also reported in the study by Ro et al. [32]; however, this was a small study and these effects were not confirmed in the much bigger sample of Rowan et al. [33]. Similar to the study in mice, children in Ro et al. were exposed to metformin in early pregnancy, whereas in Rowan et al. [33] this exposure was started in the second trimester. Hence, the timing of in utero metformin exposure could be a possible explanation for the discrepancy in these findings. Scant observational evidence in human populations found no indications of long-term health effects in the offspring OAD exposure in pregnancy. The prospective cohort study by Glueck et al. found no effect of metformin exposure in utero on weight or height at birth or adverse effects on growth or social and motor development of 109 children to mothers with PCOS in comparison to normative data for US girls and boys [46]. An increased body weight during childhood has been associated with increased risks of adult obesity and poorer cardiometabolic health [47-49]. However, the difference in weight between the treatment groups in our studies is small, and these children do not seem to differ from the normal population; hence the normal BMI $z$ scores. Therefore, it is difficult to assess the implications of this finding without longer follow-up data on clinical outcomes. The available evidence is too limited to draw firm conclusions on whether the impact of exposure to metformin on offspring depends on dosage, duration and timing during the course of pregnancy [50]. In the RCTs including women with PCOS, metformin was started during the first trimester and dosages were fixed. Whereas, in RCTs including women with GDM, dosage of metformin was based on titration according to the degree of maternal hyperglycaemia, and was started in the second half of pregnancy. Treatment indication or time of exposure does not seem to explain the effects found on offspring weight, since follow-up studies of both PCOS RCTs (metformin treatment initiated in early pregnancy) as well as GDM RCTs (metformin treatment initiated in mid-pregnancy) reported heavier offspring in the metformin group as well as no differences between the metformin and insulin groups. The same trend was found in the sensitivity analysis with PCOS trials comparing metformin to placebo, but probably as a result of the decrease in number of included children this was not statistically significant $(N=221)[28,32]$. The sensitivity meta-analysis including only GDM trials comparing metformin to insulin did result in a higher weight in the metformin group compared to insulin $(N=263)[25,29,31]$. Although our systematic review found that some indications of poorer cardiometabolic health were more prevalent 
after allocation to metformin, it is important to consider that our results were based on a limited number of heterogeneous studies with a small number of children in some of the studies. The control treatment varied according to the indication of treatment, respectively placebo in PCOS and insulin treatment in GDM women. Furthermore, all studies investigated exposure to metformin as OAD on outcomes in childhood; hence, we are unable to draw conclusions concerning other widely used OADs or whether the effects may lead to adult cardiometabolic disease. A major problem of long-term followup studies is bias due to selective attrition, but there are no clear criteria or cut-off points to grade attrition as low or high risk of bias [51]. If studies reported considerable attrition but performed statistical adjustments for differences in baseline characteristics of both mother and child, risk of attrition bias was scored 'low'.

\section{CONCLUSIONS}

On the basis of this systematic review, there is evidence suggesting increased offspring weight in childhood after maternal metformin use during gestation. The clinical implication of this finding remains unclear, since we do not have evidence on whether a minor effect on weight in these metformin-exposed children increases their risks of metabolic diseases like obesity, insulin resistance or diabetes in adolescence and later life. Heathcare providers and patients should be aware that OADs are increasingly prescribed in pregnancy without solid evidence on long-term effects on offspring. For current and future trials investigating the use of OADs in pregnancy, it is important to include long-term offspring follow-up to enable us to firmly conclude on the safety of OAD use in pregnancy and its programming effects.

\section{ACKNOWLEDGEMENTS}

Funding. V. Wekker is funded by the Dutch Heart Foundation grant: 2013T085. The funder had no part in the initiation of the study, nor in the analyses and interpretation. All authors had full access to all of the data in this study and take complete responsibility for the integrity of the data and accuracy of the data analysis. Article processing charges were funded by the authors.

Authorship. All named authors meet the International Committee of Medical Journal Editors (ICMJE) criteria for authorship for this article, take responsibility for the integrity of the work as a whole, and have given their approval for this version to be published.

Authorship Contributions. Wenneke van Weelden and Vincent Wekker performed the study selection, data extraction, data analyses and drafted the manuscript. Rebecca C. Painter designed the study, reviewed and edited the manuscript. Jacqueline Limpens performed the electronic searches and reviewed the manuscript. Leon de Wit, Hilkka Ijäs, Aleid G. van Wassenaer-Leemhuis, Tessa J. Roseboom, Bas B. van Rijn and J. Hans DeVries reviewed and edited the manuscript.

Disclosures. J. Hans DeVries is an employee of Profil Institute for Metabolic Research, Neuss, Germany. Vincent Wekker, Wenneke van Weelden, Leon de Wit, Hilkka Ijäs, Aleid G. van Wassenaer-Leemhuis, Tessa J. Roseboom, Bas B. van Rijn and Rebecca C. Painter have nothing to disclose.

Compliance with Ethics Guidelines. This article is based on previously conducted studies and does not contain any studies with human participants or animals performed by any of the authors. However, all included studies were approved by an ethical committee.

Open Access. This article is distributed under the terms of the Creative Commons Attribution-NonCommercial 4.0 International License (http://creativecommons.org/licenses/ by-nc/4.0/), which permits any noncommercial use, distribution, and reproduction in any medium, provided you give appropriate credit to the original author(s) and the source, provide 
a link to the Creative Commons license, and indicate if changes were made.

\section{REFERENCES}

1. Zhu Y, Zhang C. Prevalence of gestational diabetes and risk of progression to type 2 diabetes: a global perspective. Curr Diabetes Rep. 2016;16(1):7.

2. Hod M, Kapur A, Sacks DA, et al. The International Federation of Gynecology and Obstetrics (FIGO) Initiative on gestational diabetes mellitus: a pragmatic guide for diagnosis, management, and care. Int J Gynecol Obstet. 2015;131:S173-211.

3. International Diabetes Federation. DF diabetes atlas, 8th edn. Brussels, Belgium. 2017.

4. Bimson BE, Rosenn BM, Morris SA, Sasso EB, Schwartz RA, Brustman LE. Current trends in the diagnosis and management of gestational diabetes mellitus in the United States. J Matern Fetal Neonatal Med. 2017;30:2607-2612.

5. Coetzee EJ. Pregnancy and diabetes scenario around the world: Africa. Int J Gynecol Obstet. 2009;104(Supplement):S39-41.

6. The Guideline Development Group. Management of diabetes from preconception to the postnatal period: summary of NICE guidance. BMJ. 2008;336(7646):714-7.

7. Brown J, Martis R, Hughes B, Rowan J, Crowther CA. Oral anti-diabetic pharmacological therapies for the treatment of women with gestational diabetes. Cochrane Database Syst Rev. 2017;1:CD011967.

8. Balsells M, García-Patterson A, Solà I, Roqué M, Gich I, Corcoy R. Glibenclamide, metformin, and insulin for the treatment of gestational diabetes: a systematic review and meta-analysis. BMJ. 2015;350:h102.

9. Foretz M, Guigas B, Bertrand L, Pollak M, Viollet B. Metformin: from mechanisms of action to therapies. Cell Metab. 2014;20(6):953-66.

10. De Oliveira Baraldi C, Lanchote VL, De Jesus Antunes N, De Carvalho TMJP, Dantes Moisés EC, Duarte G, et al. Metformin pharmacokinetics in nondiabetic pregnant women with polycystic ovary syndrome. Eur J Clin Pharmacol. 2011;67(10):1027-33.

11. Schwartz RA, Rosenn B, Aleksa K, Koren G. Glyburide transport across the human placenta. Obstet Gynecol. 2015;125(3):583-8.
12. Charles B, Norris R, Xiao X, Hague W. Population pharmacokinetics of metformin in late pregnancy. Ther Drug Monit. 2006;28(1):67-72.

13. Vanky E, Zahlsen K, Spigset O, Carlsen SM. Placental passage of metformin in women with polycystic ovary syndrome. Fertil Steril. 2005;83(5):1575-8.

14. Gilbert C, Valois M, Koren G. Pregnancy outcome after first-trimester exposure to metformin: a metaanalysis. Fertil Steril. 2006;86(3):658-63.

15. Cassina $M$, Donà $M$, Di Gianantonio E, Litta $P$, Clementi M. First-trimester exposure to metformin and risk of birth defects: a systematic review and meta-analysis. Hum Reprod Update. 2014;20(5):656-69.

16. Langer O. Oral hypoglycemic agents: do the ends justify the means? Maternal Health Neonatol Perinatol. $2015 ; 1(1): 19$.

17. Barker DJP. The origins of the developmental origins theory. J Intern Med. 2007;261(5):412-7.

18. Moher D, Liberati A, Tetzlaff J, Altman DG. Preferred reporting items for systematic reviews and meta-analyses: the PRISMA statement. BMJ. 2009;339:b2535.

19. Cochrane Handbook for Systematic Reviews of Interventions Version 5.1.0 [updated March 2011]. Higgins JPT, Green S, editors: The Cochrane Collaboration, 2011; 2011.

20. Glanville JM, Lefebvre C, Miles JNV, CamossoStefinovic J. How to identify randomized controlled trials in MEDLINE: ten years on. J Med Libr Assoc. 2006;94(2):130-6.

21. Hayes R, Dennerstein L. The impact of aging on sexual function and sexual dysfunction in women: a review of population-based studies. J Sex Med. 2005;2(3):317-30.

22. Higgins JPT, Altman DG, Gøtzsche PC, et al. The Cochrane Collaboration's tool for assessing risk of bias in randomised trials. BMJ. 2011;343:d5928.

23. Ryan R, Hill S. How to GRADE the quality of the evidence. Cochrane Consumers and Communication Group. December 2016; Version 3.0.

24. Borenstein M, Hedges LV, Higgins JP, Rothstein HR. A basic introduction to fixed-effect and randomeffects models for meta-analysis. Res Synth Methods. 2010;1(2):97-111.

25. Rowan JA, Rush EC, Obolonkin V, Battin M, Wouldes T, Hague WM. Metformin in gestational diabetes: the offspring follow-up (MiG TOFU): body 
composition at 2 years of age. Diabetes Care. 2011;34(10):2279-84.

26. Battin MR, Obolonkin V, Rush E, Hague W, Coat S, Rowan J. Blood pressure measurement at two years in offspring of women randomized to a trial of metformin for GDM: follow up data from the MiG trial. BMC Pediatr. 2015;15(1):54.

27. Wouldes TA, Battin M, Coat S, Rush EC, Hague WM, Rowan JA. Neurodevelopmental outcome at 2 years in offspring of women randomised to metformin or insulin treatment for gestational diabetes. Arch Dis Child Fetal Neonatal Ed. 2016;101:F488-93.

28. Carlsen SM, Martinussen MP, Vanky E. Metformin's effect on first-year weight gain: a follow-up study. Pediatrics. 2012;130(5):e1222-6.

29. Ijäs H, Vaarasmaki M, Saarela T, Keravuo R, Raudaskoski T. A follow-up of a randomised study of metformin and insulin in gestational diabetes mellitus: growth and development of the children at the age of 18 months. BJOG. 2015;122(7):994-1000.

30. Tertti K, Eskola E, Rönnemaa T, Haataja L. Neurodevelopment of two-year-old children exposed to metformin and insulin in gestational diabetes mellitus. J Dev Behav Pediatr. 2015;36(9):752-7.

31. Tertti K, Toppari J, Virtanen HE, Sadov STR. Metformin treatment does not affect testicular size in offspring born to mothers with gestational diabetes. Rev Diabet Stud. 2016;13(1):59-65.

32. Rø TB, Ludvigsen HV, Carlsen SM, Vanky E. Growth, body composition and metabolic profile of 8-year-old children exposed to metformin in utero. Scand J Clin Lab Invest. 2012;72(7):570-5.

33. Rowan JA, Rush EC, Plank LD, et al. Metformin in gestational diabetes: the offspring follow-up (MiG TOFU): body composition and metabolic outcomes at 7-9 years of age. BMJ Open Diabetes Res Care. 2018;6(1):e000456.

34. Hanem LGE, Stridsklev S, Júlíusson PB, et al. Metformin use in PCOS pregnancies increases the risk of offspring overweight at 4 years of age: follow-up of two RCTs. J Clin Endocrinol Metab. 2018;103(4):1612-21.

35. Chiswick CA, Reynolds RM, Denison FC, et al. Efficacy of metformin in pregnant obese women: a randomised controlled trial. BMJ Open. 2015;5(1):e006854.

36. Feig DS, Murphy K, Asztalos E, et al. Metformin in women with type 2 diabetes in pregnancy (MiTy): a multi-center randomized controlled trial. BMC Pregnancy Childbirth. 2016;16(1):173.
37. Vanky E, Stridsklev S, Heimstad R, et al. Metformin versus placebo from first trimester to delivery in polycystic ovary syndrome: a randomized, controlled multicenter study. J Clin Endocrinol Metab. 2010;95(12):E448-55.

38. Rowan JA, Hague WM, Gao W, Battin MR, Moore MP. Metformin versus insulin for the treatment of gestational diabetes. N Engl J Med. 2008;358(19): 2003-15.

39. Ijäs H, Vääräsmäki M, Morin-Papunen L, et al. Metformin should be considered in the treatment of gestational diabetes: a prospective randomised study. BJOG Int J Obstet Gynaecol. 2011;118(7): 880-5.

40. Tertti K, Ekblad U, Koskinen P, Vahlberg T, Rönnemaa T. Metformin vs. insulin in gestational diabetes. A randomized study characterizing metformin patients needing additional insulin. Diabetes Obes Metab. 2013;15(3):246-51.

41. Vanky E, Salvesen KÅ, Heimstad R, Fougner KJ, Romundstad P, Carlsen SM. Metformin reduces pregnancy complications without affecting androgen levels in pregnant polycystic ovary syndrome women: results of a randomized study. Hum Reprod. 2004;19(8):1734-40.

42. Dewailly D, Tarlatzis R. Revised 2003 consensus on diagnostic criteria and long-term health risks related to polycystic ovary syndrome. Fertil Steril. 2004;81(1):19-25.

43. WHO Multicentre Growth Reference Study Group. WHO Child Growth Standards: Length/height-forage, weight-for-age, weight-for-length, weight-forheight and body mass index-for-age: Methods and development. Geneva: World Health Organization, 2006. p. 312

44. Salomäki H, Vähätalo LH, Laurila K, et al. Prenatal metformin exposure in mice programs the metabolic phenotype of the offspring during a high fat diet at adulthood. PLoS One. 2013;8(2):e56594.

45. Lee H-S. Impact of maternal diet on the epigenome during in utero life and the developmental programming of diseases in childhood and adulthood. Nutrients. 2015;7(11):9492-507.

46. Glueck CJ, Goldenberg N, Pranikoff J, Loftspring M, Sieve L, Wang P. Height, weight, and motor-social development during the first 18 months of life in 126 infants born to 109 mothers with polycystic ovary syndrome who conceived on and continued metformin through pregnancy. Hum Reprod. 2004;19(6):1323-30.

47. Guo SS, Wu W, Chumlea WC, Roche AF. Predicting overweight and obesity in adulthood from body 
mass index values in childhood and adolescence. Am J Clin Nutr. 2002;76(3):653-8.

48. Simmonds M, Llewellyn A, Owen CG, Woolacott N. Predicting adult obesity from childhood obesity: a systematic review and meta-analysis. Obes Rev. 2015;17(2):95-107.

49. Field AE, Cook NR, Gillman MW. Weight status in childhood as a predictor of becoming overweight or hypertensive in early adulthood. Obes Res. 2005;13(1):163-9.
50. Hertz-Picciotto I, Pastore LM, Beaumont JJ. Timing and patterns of exposures during pregnancy and their implications for study methods. Am J Epidemiol. 1996;143(6):597-607.

51. Fewtrell MS, Kennedy K, Singhal A, et al. How much loss to follow-up is acceptable in long-term randomised trials and prospective studies? Arch Dis Child. 2008;93(6):458-61. 